\title{
Enhancement of recurrent inhibition by intravenous administration of L-acetylcarnitine in spastic patients
}

\author{
Riccardo Mazzocchio, Marco Schieppati, Chiara Scarpini, Alessandro Rossi
}

\begin{abstract}
The recurrent inhibition of the soleus alpha-motoneurons at rest, evaluated by a specially designed method of paired $\mathbf{H}$ reflexes, was estimated in 10 patients with spastic paraparesis. In three of these patients, Renshaw cell activity produced inhibition of the corresponding alphamotor neurons comparable to that obtained in normal subjects, while the inhibition was reduced in five and absent in two. The effects of intravenously administered L-acetylcarnitine on the activity of Renshaw cells were studied in these patients. In all patients except the two with no evidence of recurrent inhibition, L-acetylcarnitine was found to significantly increase the amount of recurrent inhibition. Its effect became evident at about 30 minutes, reached a maximum around 50 minutes and vanished about 70 minutes from the onset of administration. A significant correlation was found between Renshaw cell activity and the ability of the drug to increase it. L-acetylcarnitine appeared to act specifically by enhancing recurrent inhibition, since no variation in the excitability of the monosynaptic reflex arc was observed.
\end{abstract}

Recurrent inhibition, first described by Renshaw, ${ }^{1}$ is mediated by axon collaterals of motor neurons (MNs) projecting to Renshaw cell (RC) inhibitory interneurons, which in turn project back to alpha- ${ }^{2-4}$ and gamma- $^{5}$ MNs, Ia inhibitory interneurons ${ }^{6}$ and other $\mathrm{RCs} .{ }^{7}$ One of the suggested roles for RC is as a variable gain regulator of $\mathrm{MN}$ output from descending fibre inputs. ${ }^{8}$

This possible role in motor control has been particularly researched in normal ${ }^{9}$ and spastic subjects. ${ }^{10-12}$ From the latter studies it can be inferred that supraspinal control of RCs was lacking during voluntary contraction, while recurrent inhibition at rest, if it changed at all, was decreased only in a limited number of patients.

Although current evidence does not support the idea that exaggeration of passively induced stretch reflexes in spastic patients may be related to a decrement in RC activity, it is reasonable to hypothesise that strengthening of the inhibitory activity of RCs could contribute to reducing the hyperactive stretch reflexes in these patients.
Preliminary results ${ }^{13}$ have demonstrated that the intravenous administration of L-acetylcarnitine (L-AC), a well-known cholinomimetic drug ${ }^{14}$ is capable of increasing the recurrent inhibition of soleus $\mathrm{MNs}$ in normal subjects. It was therefore of particular interest to study the effects of this drug on recurrent inhibition in spastic subjects.

\section{Materials and methods}

Experiments were performed on 10 patients (eight males and two females, aged 13-58 years) who gave their informed consent after agreement from the local Ethical Committee. They were selected from a population of 17 subjects that participated in a recent investigation of the activity of soleus-coupled RCs in spasticity of spinal origin. ${ }^{12}$ Of the original 17 patients, four were excluded from this study because they were unwilling to enter an acute pharmacological trial and three because of protocol noncompliance.

The new population presented with spastic paraparesis, its duration ranging from two to 25 years. The clinical picture was very similar in all patients, differing only in its severity: a degree of paresis and increased tendon jerk reflexes and tone were present in both lower limbs. One patient (Case 1 in the table) had a complete post-traumatic transection of the cord at low thoracic level; another (Case 2) had a compressive myelopathy from intervertebral disc protrusion at $\mathrm{C5}-\mathrm{C} 6$; the remaining eight patients suffered from hereditary spastic paraparesis of Strumpell-Lorrain (Cases 3-10): the diagnosis was based on inheritance, lack of either electromyographic alterations of the peripheral nervous system or changes in brain computerised tomography (CT) and/or magnetic resonance imaging (MRI) scans. (See table.)

\section{Method of estimating recurrent inhibition}

The subjects were seated on an examination chair, the knee and ankle joint at 110 and 90 deg respectively. The electromyographic activity of the soleus was recorded through surface electrodes set $2 \mathrm{~cm}$ apart, placed posteriorly on the lower third of the leg. The soleus $\mathrm{H}$ reflex was obtained by stimulating the tibial nerve at the popliteal fossa with rectangular pulses of $1 \mathrm{~ms}$ duration. The same unipolar electrode provided the conditioning and test stimuli.

Recurrent inhibition was evaluated by the method originally developed by Bussel and Pierrot-Deseilligny ${ }^{15}$ and extensively described 


\begin{tabular}{|c|c|c|c|c|c|c|c|c|c|c|}
\hline \multirow[b]{2}{*}{ Case } & \multirow[b]{2}{*}{ Sex } & \multirow[b]{2}{*}{ Age } & \multirow[b]{2}{*}{ Diagnosis } & \multirow[b]{2}{*}{$\begin{array}{l}\text { Duration of } \\
\text { disease in years }\end{array}$} & \multirow[b]{2}{*}{$\begin{array}{l}\text { Clinical } \\
\text { spasticity }\end{array}$} & \multirow[b]{2}{*}{$H / M$ ratio } & \multirow[b]{2}{*}{$\begin{array}{l}\text { Pattern of } \\
H^{\prime} \text { variations }\end{array}$} & \multicolumn{3}{|c|}{$L-A C$ maximal effect } \\
\hline & & & & & & & & $\begin{array}{l}H_{\%}^{\prime} \text { refle } \\
\%\end{array}$ & 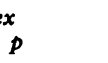 & $\begin{array}{l}\text { Time in } \\
\text { mins }\end{array}$ \\
\hline $\begin{array}{r}1 \\
2 \\
3 \\
4 \\
5 \\
6 \\
7 \\
8 \\
9 \\
10\end{array}$ & $\begin{array}{l}M \\
M \\
M \\
M \\
M \\
M \\
F \\
F \\
M \\
M\end{array}$ & $\begin{array}{l}57 \\
56 \\
43 \\
54 \\
46 \\
58 \\
42 \\
19 \\
13 \\
26\end{array}$ & $\begin{array}{l}\text { ST } \\
\text { CC } \\
\text { SL } \\
\text { SL } \\
\text { SL } \\
\text { SL } \\
\text { SL } \\
\text { SL } \\
\text { SL } \\
\text { SL }\end{array}$ & $\begin{array}{r}10 \\
21 \\
25 \\
8 \\
21 \\
18 \\
24 \\
9 \\
10 \\
8\end{array}$ & $\begin{array}{l}++++ \\
+++ \\
+++ \\
++ \\
+ \\
++ \\
+++ \\
++ \\
+++ \\
+++\end{array}$ & $\begin{array}{l}0.9 \\
0.9 \\
0.9 \\
0.8 \\
0.9 \\
0.9 \\
0.8 \\
0.8 \\
0.9 \\
0.9\end{array}$ & $\begin{array}{l}\text { Plateau-like } \\
\text { Bell-shaped } \\
\text { Plateau-like } \\
\text { Bell-shaped } \\
\text { Bell-shaped } \\
\text { Plateau-like } \\
\text { Plateau-like } \\
\text { Plateau-like } \\
\text { Straight line } \\
\text { Straight line }\end{array}$ & $\begin{array}{l}82 \\
88 \\
81 \\
33 \\
71 \\
79 \\
61 \\
71 \\
93 \\
95\end{array}$ & $\begin{array}{l}<0.05 \\
<0.01 \\
<0.025 \\
<0.001 \\
<0.005 \\
<0.001 \\
<0.001 \\
<0.01 \\
\text { NS } \\
\text { NS }\end{array}$ & $\begin{array}{l}35-45 \\
35-45 \\
25-35 \\
45-55 \\
45-55 \\
45-55 \\
55-65 \\
55-65 \\
25-35 \\
15-25\end{array}$ \\
\hline
\end{tabular}

Diagnosis: ST = Spinal Transection; CC = Cord Compression; SL = Strumpell-Lorrain Disease. L-AC Maximal Effect: $\mathrm{H}^{\prime}$ reflex amplitude expressed as a \% of $\mathrm{H}^{\prime}$ before $\mathrm{L}-\mathrm{AC}$ administration; Time from onset of administration.

in a previous paper. ${ }^{16}$ Briefly, RCs were activated by a conditioning reflex response (H1) of the "corresponding" alpha-MNs of the soleus elicited by an electrical conditioning stimulus (S1), and the resulting inhibitory effect was evaluated by the test reflex response $\left(\mathbf{H}^{\prime}\right)$ elicited by a successive supramaximal stimulus (SM) of the same nerve, $10 \mathrm{~ms}$ after the conditioning stimulus. The collision of the $\mathrm{H} 1$ reflex with the antidromic volley following the supramaximal stimulation prevents the appearance of the $\mathrm{H} 1$ reflex response and opens the way for an orthodromic monosynaptic reflex response $\left(\mathrm{H}^{\prime}\right)$ to the same supramaximal test stimulus.

The stimulation protocol was as follows: a) the conditioning stimulus $S 1$ was given alone to check the size of the $\mathrm{H} 1$ conditioning reflex; $b$ ) the stimuli $S 1+S M$ followed 10 s later. The sequences $a$ and $b$ were repeated with randomly varied intensities of the $S 1$ conditioning stimulus to study the effects of different amplitudes of the $\mathrm{Hl}$ conditioning discharge on the $\mathrm{H}^{\prime}$ test reflex. In this way, the $\mathrm{H}^{\prime} / \mathrm{Hl}$ curve was obtained by plotting the amplitude of the $\mathrm{H}^{\prime}$ reflexes as a function of the amplitude of the $\mathrm{H} 1$ reflexes. All values were expressed as a percentage of the maximal motor response (Mmax).

\section{Method of estimating the effect of $L-A C$ on recurrent inhibition}

All patients had been free of drugs for two months before participating in the study. To test the effects of $\mathrm{L}-\mathrm{AC}$ on the $\mathrm{H}^{\prime}$ reflex, the intensity of $\mathrm{S} 1$ conditioning stimulus was adjusted to have an $\mathrm{Hl}$ conditioning reflex about $80 \%$ of its maximal amplitude. The $\mathbf{H}^{\prime}$ reflexes, evoked in this way, were then acquired at a rate of $6-8$ per minute throughout the experimental session.

L-Acetylcarnitine (Nicetile ${ }^{\circledR}$ ) was obtained from Sigma-Tau (Pomezia, Italy) $2000 \mathrm{mg}$ of the drug were dissolved in a volume of $100 \mathrm{ml}$ of $0.9 \%$ saline solution. At the beginning of the experiments, two iv infusion sets were prepared, connected to the patient via a twoway tap. The first bottle contained saline, the second the solution of L-AC. A continuous iv infusion of saline was started after setting the appropriate stimulation parameters. L-AC was then administered for 11-17 minutes (mean 14.5) after which saline infusion was resumed. It is important to stress that, although the order of treatment (saline, L-AC, saline) was constant, the patients could not realise when L-AC replaced saline and vice versa. Before, during and after $\mathrm{L}-\mathrm{AC}$ administration, $\mathrm{Hl}$ and $\mathrm{H}^{\prime}$ reflexes were randomly evoked.

The amplitude of $\mathrm{H}$ reflexes was automatically measured (peak to peak) by computer. The $\mathrm{Hl}$ and $\mathrm{H}^{\prime}$ reflexes occurring within every $10 \mathrm{~min}$ period from the start of the experiment were then averaged, and the results obtained during and after L-AC plotted as a function of the time elapsed from the onset of administration, in correspondence with the centre of each time-interval. For example, the mean value at 50 minutes comprises those reflexes occurring from 45 to 55 minutes. The values of the $\mathrm{H}^{\prime}$ reflexes recorded during and after L-AC administration were expressed as a percentage of the values of the $\mathrm{H}^{\prime}$ reflexes evoked before L-AC administration, which were considered as controls. The same criterion was used for the $\mathrm{Hl}$ reflexes. The changes in the $\mathrm{H}^{\prime}$ and $\mathrm{Hl}$ amplitude induced by L-AC administration were therefore evaluated by comparison with the pre-infusion $\mathrm{H}^{\prime}$ and $\mathrm{Hl}$ values. The mean and standard deviation (SD) were computed for all the single reflexes evoked in a given time interval, and compared by the two-tailed Student's $t$ test both within and between patients.

The $\mathrm{H}^{\prime} / \mathrm{Hl}$ curve and the effect of L-AC on $\mathrm{H}^{\prime}$ amplitude were studied only in one normal subject in this investigation. The results are entirely consistent with those we have already reported. ${ }^{13}$

\section{Results}

Figure 1A illustrates the typical pattern of variations in the $\mathrm{H}^{\prime}$ test reflex amplitude as the $\mathrm{Hl}$ conditioning reflex amplitude was increased by augmenting the strength of the $S 1$ stimulus in a normal subject. At low $\mathrm{Hl}$ reflex amplitude, the $\mathrm{H}^{\prime}$ reflex closely followed $\mathrm{Hl}$ up to a specific value ( $H^{\prime}$ max $)$ beyond which, as the $H$ continued to increase, there was a gradual decrease in the $\mathbf{H}^{\prime}$ reflex amplitude. The effects of the administration of L-AC on the amplitude of the $\mathrm{H}^{\prime}$ (fig $1 \mathrm{~B}$ ) and $\mathrm{Hl}$ (fig $1 \mathrm{C}$ ) reflexes are also illustrated in the same figure. These effects were obtained by $\mathrm{Sl}$ stimulation yielding an $\mathrm{Hl}$ of about $80 \%$ of its maximum amplitude. In agreement with our preliminary findings, ${ }^{13}$ a 
Figure 1 Pattern of variations of the $H^{\prime}$ test reflex after the $\mathrm{HI}$ conditioning discharge and the effect of

$L-A C$ on the $H^{\prime}$ and $H 1$ reflexes in a normal subject. In $A$, the amplitude of the $H^{\prime}$ reflex is plotted against that of the $H 1$ reflex (both expressed as a percentage of Mmax). Each point is the mean of 5

measurements. The timecourse of the $H^{\prime}(B)$ and $H 1$ (C) reflexes, expressed as a percentage of the $H^{\prime}$ and $H 1$ reflexes

respectively evoked before $L-A C$ administration, is plotted as a function of the time from the onset of $L$ $A C$ administration. Each point is the mean of 15 measurements $\pm 1 S D$.

Significant points are indicated by * $(P<0.05)$.
Figure 2 Pattern of variations of the $H^{\prime}$ test reflex $(A)$ and the effect of $L-A C$ on the $H^{\prime}(B)$ and $H 1$ ( $C$ ) reflexes in Case 4. $A, B$ and $C$ as in Fig 1.
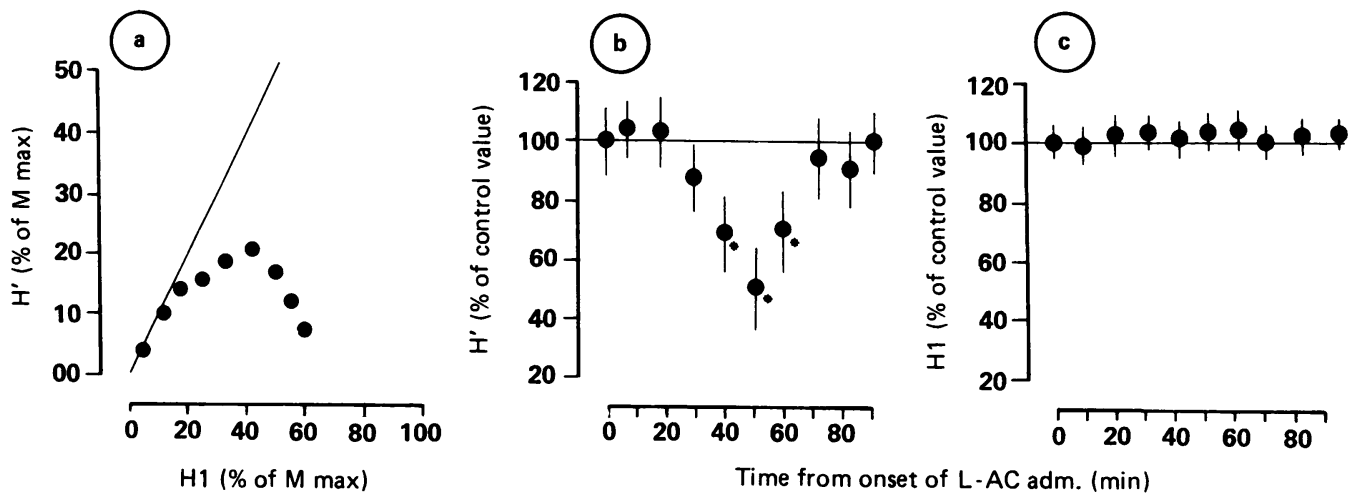

decrease in the amplitude of $\mathrm{H}^{\prime}$ became evident at about 30 minutes, and was greatest around 50 minutes from the onset of L-AC administration. The effect was over between 70 and 80 minutes when the amplitude of $\mathrm{H}^{\prime}$ attained the values observed before administering the drug (control values). On the contrary, no significant variation in the amplitude of $\mathrm{Hl}$ at the same time intervals was present.

Three representative examples of that observed in spastic patients are illustrated in figs 2, 3 and 4 . The pattern reported in fig $2 \mathrm{~A}$ was observed in three patients (Cases 2, 4 and 5 in the table). In the example illustrated (Case 4), the $\mathrm{H}^{\prime}$ reflex, having reached its maximum amplitude was only weakly depressed by further augmentation of $\mathrm{Hl}$. In all the three patients of this group, the $\mathrm{H}^{\prime}$ max ranged between 10 and $15 \%$ of Mmax. L-AC induced in the same case (fig 2B), as in the other two, a significant decrease in the amplitude of $\mathbf{H}^{\prime}$ which was apparent at about 30 minutes, greatest around 50 minutes and vanished about 80 minutes from the onset of administration. The mean value of greatest $\mathrm{H}^{\prime}$ inhibition, observed within 35-55 minutes from the start of L-AC administration, was $36 \pm 28 \%$ of the control values in these patients (table). No effect of the drug on the $\mathrm{Hl}$ conditioning reflex was evident in the same patient (fig 2C) or in the others.

Figure 3A illustrates a representative example of the pattern observed in five patients (Cases 1, 3, 6, 7 and 8). The $\mathrm{H}^{\prime}$ reflex reached a plateau and showed no sign of successive reduction as $\mathrm{Hl}$ continued to increase. In these patients, the $\mathrm{H}^{\prime}$ max ranged between 35 and $45 \%$ of Mmax. The effects of L-AC on $\mathrm{H}^{\prime}$ (fig 3B) and $\mathrm{Hl}$ (fig 3C) reflexes in one patient (Case 6 ) are shown. The mean value of the greatest inhibitory effect induced by L-AC administration on $\mathrm{H}^{\prime}$, within 35-55 minutes, was $25 \pm 9 \%$ in the five patients of this group.

Figure 4 illustrates the results in two patients (Cases 9 and 10). In fig 4A (Case 9), the amplitude of $\mathrm{H}^{\prime}$ continuously increased when $\mathrm{Hl}$ was increased and showed no sign of diminishing. The administration of L-AC produced no significant effect on the amplitudes of $\mathrm{H}^{\prime}$ (fig 4B) and $\mathrm{Hl}$ (fig 4C) reflexes at any time interval

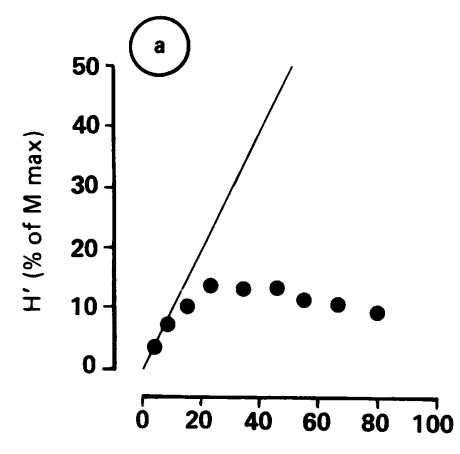

H1 (\% of $M$ max)

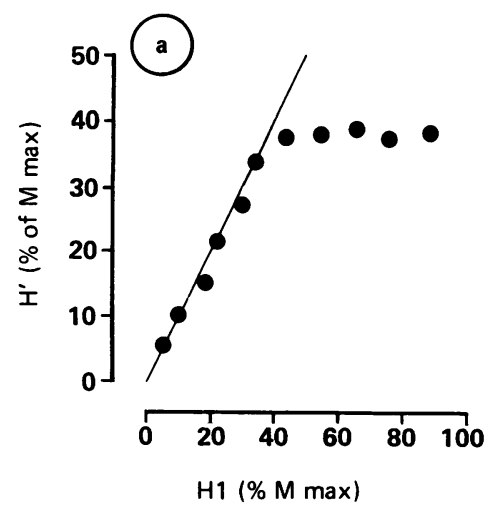

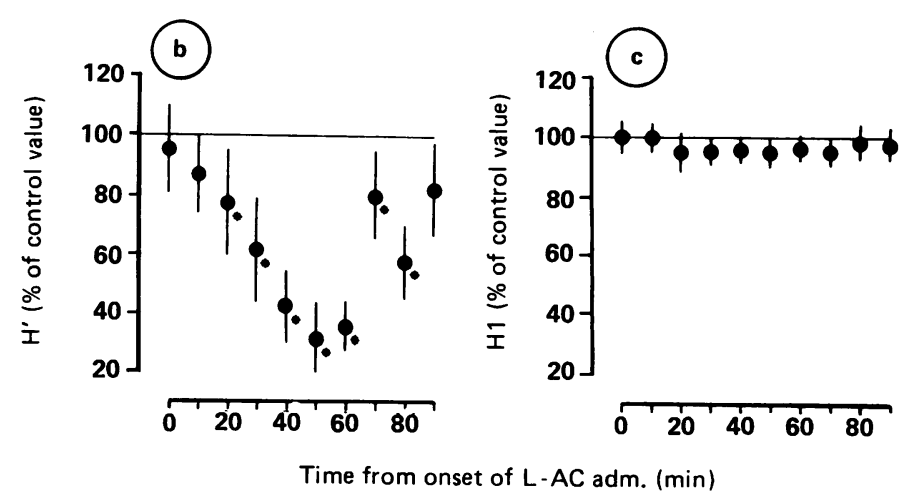

(b)

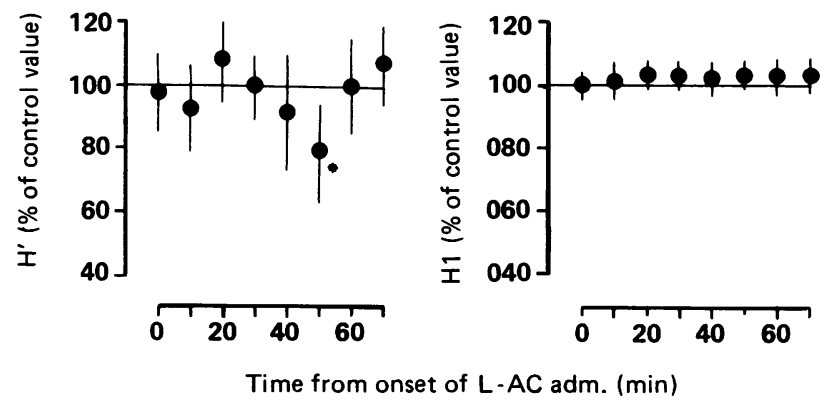

variations of the $H^{\prime}$ test reflex $(A)$ and the effect of $L-A C$ on the $H^{\prime}(B)$ and $H 1(C)$ reflexes in Case 6. $A, B$ and $C$ as in Fig 1 . 
Figure 4 Pattern of variations of the $H^{\prime}$ test reflex $(A)$ and the effect of $L-A C$ on the $H^{\prime}(B)$ and $H 1(C)$ reflexes in Case 9. $A, B$ and $C$ as in Fig 1.

Figure 5 Time-course (grand mean) of the effect of $L-A C$ on $H^{\prime}(A)$ and $H 1(B)$ reflexes obtained by averaging all the values from the eight patients who exhibited a sizable recurrent inhibition in control conditions. Significant points are indicated by * $(P<0.05)$

Figure 6 Relationship between the amplitude of $H^{\prime}$ test reflex expressed as conditioning reflex (abscissa) and the percentage decrement of $H^{\prime}$ test reflex produced by $L$ $A C$ (ordinate) in all the patients. The equation of the straight line is $y=0.57 x-5$, $r=0.79(P<0.01)$. a percentage of $\mathrm{HI}$
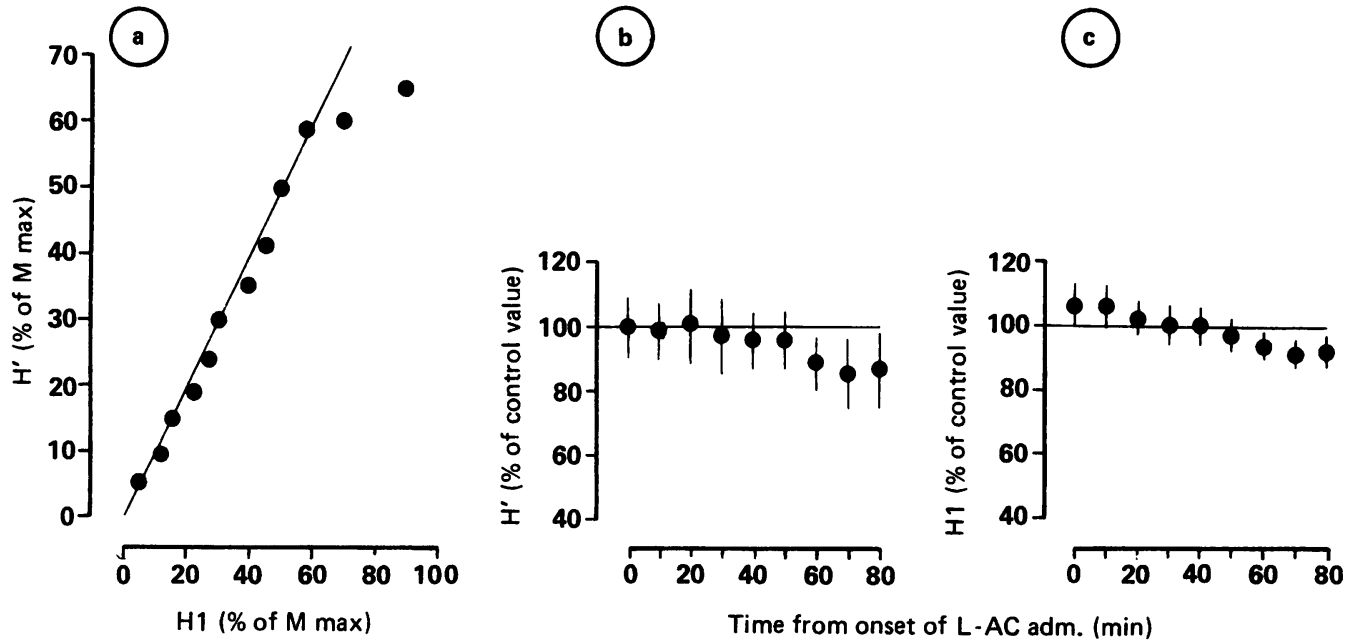

in the range explored.

The general time course of the effects of L$A C$, the grand mean variation in the amplitudes of $\mathrm{H}^{\prime}$ (fig $5 \mathrm{~A}$ ) and $\mathrm{Hl}$ (fig $5 \mathrm{~B}$ ) reflexes after the administration of L-AC, from all the patients except Cases 9 and 10, where there was no evidence of recurrent inhibition, is shown in fig 5. The value of the greatest inhibition in $\mathrm{H}^{\prime}$ amplitude, the time interval at which it occurred and the relative Student's $t$ values for each patient are reported in the table, along
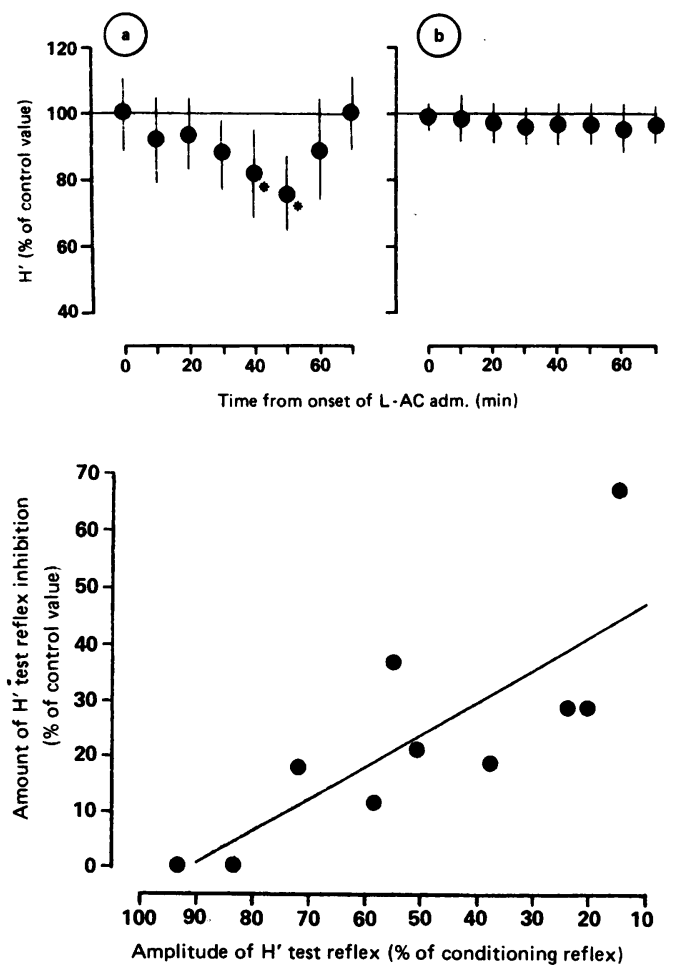

Figure 7 Pattern of $H^{\prime}$ variations following administration of $L-A C$ $(A)$ and saline solution (B) administration (Case 5). A significant point is marked by ${ }^{\star}$ $(P<0.005)$. with the $\mathrm{H} / \mathrm{M}$ ratios and the various patterns of $\mathrm{H}^{\prime}$ variations.

To decide whether the changes in $\mathrm{H}^{\prime}$ reflex produced by L-AC were related to the control $\mathrm{H}^{\prime}$ amplitude (that is, before L-AC administration), we plotted the maximal amounts of inhibition induced by $\mathrm{L}-\mathrm{AC}$ versus the $\mathrm{H}^{\prime}$ amplitude measured before administering the drug for each single patient. Figure 6 shows that there is a clear-cut and significant regression between the two variables. Assuming that the ratio $\mathrm{H}^{\prime} / \mathrm{Hl}$ in part reflects the amount of recurrent inhibition, it becomes apparent that the ability of the drug to decrease the $\mathrm{H}^{\prime}$ amplitude is significantly dependent on the level of RC activity before L-AC administration in each subject.

\section{Control experiments}

Saline solution alone was administered in three patients (Cases 5, 7 and 6 see table). In fig 7, the effects of L-AC (fig 7A) and of saline (fig 7B) on $\mathrm{H}^{\prime}$ amplitude in Case 5 are compared. In no case did saline produce significant changes in the amplitude of the $\mathrm{H}^{\prime}$ reflexes.

The possibility was also considered that the lack of effect of $\mathrm{L}-\mathrm{AC}$ on the $\mathrm{Hl}$ conditioning reflex could, in part, depend on its being of greater amplitude than $\mathrm{H}^{\prime}$. It is in fact known that the susceptibility to conditioning events of $\mathrm{H}$ reflexes is partly dependent on their size. ${ }^{17}$ Therefore, the effect of L-AC on unconditioned $\mathrm{H}$ reflexes, of amplitude equal to the $\mathrm{H}^{\prime}$ control values, was tested in one patient (Case 6). No significant effect of the drug on unconditioned $\mathrm{H}$ reflexes of such amplitude was observed.

\section{Adverse reactions}

None of the patients complained of any adverse reactions during or after $\mathrm{L}-\mathrm{AC}$ administration. A burning sensation at the injection site was reported in some cases.

\section{Discussion}

Our findings clearly show that the iv administration of L-AC induces a powerful enhancement of recurrent inhibition of the soleus MNs in most spastic subjects, as measured by the decrease in $\mathrm{H}^{\prime}$ test reflex.

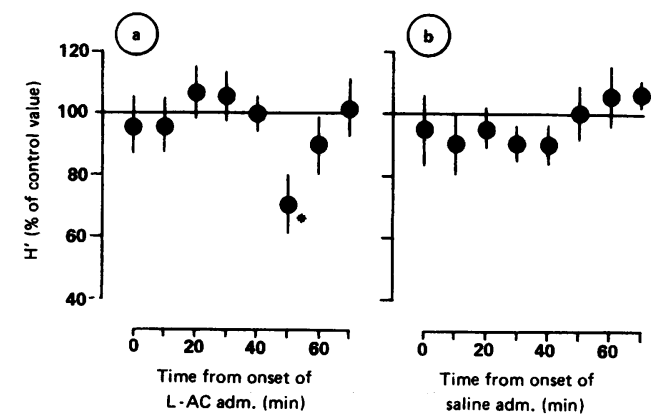


From the findings of Katz and PierrotDeseilligny $^{10}$ and Katz, ${ }^{11}$ and from our previously reported data, ${ }^{12}$ it appears that spastic patients exhibit three different patterns of behaviour of the $\mathrm{H}^{\prime}$ test reflex in relation to the amplitude of $\mathrm{Hl}$ conditioning reflexes: (a) a "bell-shaped" pattern, similar to that observed in normal subjects, in which the $\mathrm{H}^{\prime}$ amplitude, having reached its maximum, gradually decreases as the $\mathrm{Hl}$ amplitude is progressively augmented. A pattern of this kind indicates a normal or even increased RC activity at rest, in view of the monosynaptic reflex arc hyperexcitability of these patients. ${ }^{10}$ In our previous study,$^{12}$ this pattern was observed in nine of 17 patients (53\% of cases); (b) a "plateau-like" pattern, in which the $\mathrm{H}^{\prime}$ amplitude having attained its maximum remains unchanged in spite of the progressive increase in $\mathrm{Hl}$ amplitude. This pattern was observed in six of 17 patients ( $35 \%$ of cases). The fact that there is no evidence of a decay phase of the $\mathrm{H}^{\prime}$ test reflex in these patients could be related to a reduced $\mathrm{RC}$ activity, the $\mathrm{H}^{\prime}$ reflex thus being primarily exposed to the action of the afterhyperpolarisation (AHP) that MNs are undergoing after the conditioning discharge. ${ }^{11}{ }^{12}$ This behaviour, however, could also be explained by the hyperexcitability of the monosynaptic reflex $\operatorname{arc}^{10}$ (c) a "straight line" pattern (observed in two of 17 patients, that is, $12 \%$ of cases) in which the $\mathrm{H}^{\prime}$ amplitude increases in parallel with the $\mathrm{Hl}$ amplitude showing no sign of decreasing. An "extended" susceptibility of alpha-MNs to Ia excitatory effects, coupled with a complete loss of recurrent inhibition, could make the Ia test volley effective enough to overcome the AHP to which MNs are subject after the conditioning discharge, thus reactivating them all. Although it is not possible to know to what extent each of these factors contributes to such observed behaviour, we can conclude, at least for spastic patients with "plateau-like" and "straight line" patterns, that RC inhibitory activity is unable to restrain the "corresponding" MNs which are in a hyperactive state.

In a preliminary study performed in normal subjects, ${ }^{13}$ we showed that the iv administration of L-AC remarkably enhances recurrent inhibition of soleus MNs. In the present paper, a similar effect has also been demonstrated in spastic subjects. In the patients exhibiting both a "bell-shaped" and a "plateau-like" pattern $(80 \%$ of the present cases), L-AC produced a significant decrease in the amplitude of the $\mathbf{H}^{\prime}$ reflex. On administering $2000 \mathrm{mg}$ of the drug in about 15 minutes, the effect was evident at about 30 minutes, maximum around $50 \mathrm{~min}$ utes and vanished between 60 and 70 minutes from the start of administration.

In the two patients with a "straight line" pattern, in whom there was no evidence of recurrent inhibition (that is, the $\mathbf{H}^{\prime}$ reflex continuously increased with increasing $\mathrm{Hl}$ ), $\mathrm{L}$ $\mathrm{AC}$ was unable to produce any significant effect on the $\mathrm{H}^{\prime}$ amplitude.

In all patients, the administration of L-AC did not significantly modify the amplitude of the $\mathrm{Hl}$ conditioning reflex. Since its amplitude was usually much greater than that of $\mathrm{H}^{\prime}$, it could be argued that this might determine a lower susceptibility of $\mathrm{Hl}$ to the drug with respect to $\mathrm{H}^{\prime}$. This, however, can be ruled out since no effect was observed when L-AC was tested on unconditioned $\mathrm{H}$ reflexes, the amplitude of which was equal to that of the $\mathrm{H}^{\prime}$ test reflex. These observations exclude the possibility that L-AC influences $M N$ excitability, neuromuscular transmission and presynaptic inhibition on Ia afferent fibres. Thus, we can hypothesise that an increase in recurrent inhibition is the main factor responsible for the depression of the $\mathrm{H}^{\prime}$ amplitude produced by $\mathrm{L}-\mathrm{AC}$. This conclusion is strengthened by the significant correlation between the amount of $\mathrm{H}^{\prime}$ inhibition produced by the drug and the level of RC activity before L-AC administration. The fact that the lower the recurrent inhibition, the less the drug is effective, indirectly supports the hypothesis that spastic subjects with a "straight line" pattern of $\mathrm{H}^{\prime}$ variations lack recurrent inhibition.

A further observation is prompted by the fact that L-AC is capable of enhancing recurrent inhibition also in patients with a "bell-shaped" pattern, in whom RC activity is supposed to be increased. ${ }^{10}$ This indicates that there is still margin for additional increases in RC activity even in these cases. The possibility of strengthening such inhibitory activity may have some weight in resetting the balance between excitatory and inhibitory inputs to spinal MNs in spastic patients.

It must be stressed that the patients selected for this study represent a fairly homogeneous model of spasticity in that the spinal cord was the principal site of disease and the nature of spasticity was similar among the subjects. Since spasticity can arise from a multitude of lesions and its characteristics depend heavily on the precise localisation and combination of lesions, our results might not be generalised.

It is worth emphasising that the effects of LAC on recurrent inhibition were also observed in a patient with complete transection of the cord at low thoracic level. This suggests that the drug exerts its action directly at spinal level.

Our conclusion that the effects of L-AC on the $\mathrm{H}^{\prime}$ test reflex result from an increase in $\mathrm{RC}$ activity is coherent with the demonstration that these interneurons have both nicotinic and muscarinic excitatory receptors ${ }^{18}$ which may be activated by systemic administration of blood-brain barrier-penetrating cholinergic agonists. ${ }^{19}$

Dr R Mazzocchio received a grant from SigmaTau, Italy. This work was partially supported by a grant from Regione Toscana and the Italian MPI.

1 Renshaw B. Influence of discharge of motoneurons upon excitation of neighbouring motoneurons. $J$ Neurophysiol 1941;4:167-83.

2 Renshaw B. Central effects of centripetal impulses in axon of spinal ventral roots. J Neurophysiol 1946;9:191-204.

3 Eccles JC, Fatt P, Koketsu K. Cholinergic and inhibitory synapses in a pathway from motor-axon collaterals to motoneurons. J Physiol 1954;126:524-62.

4 Wilson VJ, Talbot WH, Diecke FPJ. Distribution of ilson VJ, Talbot WH, Diecke FPJ. Distribution of recurrent facilitation and inhib 
5 Ellaway PH. Recurrent inhibition of fusimotor neurones exhibiting background discharges in the decerebrate and exhibiting background discharges in the
spinal cat. J Physiol 1971;216:419-29.

6 Hultborn H, Jankowska E, Lindström S. Recurrent inhibition from motor axon collaterals of transmission in the I inhibitory pathway to motoneurones. J Physiol 1971;215:591-612.

7 Ryall RW. Renshaw cell mediated inhibition of Renshaw cells: pattern of excitation and inhibition from impulses in motor axon collaterals. J Neurophysiol 1970;33:257-70.

8 Hultborn $\mathrm{H}$, Lindström $\mathrm{S}$, Wigström $\mathrm{H}$. On the function of recurrent inhibition in the spinal cord. Exp Brain Res 1979;37:399-403.

9 Hultborn H, Pierrot-Deseilligny E. Changes in recurrent inhibition during voluntary soleus contractions in man
studied by an H-reflex technique. J Physiol 1979;297: 229-51.

10 Katz R, Pierrot-Deseilligny E. Recurrent inhibition of alpha-motoneurons in patients with upper motor neuron lesions. Brain 1982;105:103-24.

11 Katz R. Etude chez l'Homme et chez le Chat de l'organisation fonctionelle de l'inhibition récurrente de Renshaw. These de doctorat d'etat, 1984 University of Paris.
12 Mazzocchio R, Rossi A. Recurrent inhibition in human spinal spasticity. Ital J Neurol Sci 1989;10:337-47.

13 Schieppati M, Gritti I, Mazzocchio R, Rossi A, Mancia M. Motoneurone recurrent inhibition is enhanced by $L$ acetylcarnitine in humans. Electromyogr clin Neurophysiol 1989;29:73-80.

14 Reed KW, Murray WJ, Roche EB. Acetylcarnitine and cholinergic receptors. J Pharm Sci 1980;69:1065-8.

15 Bussel B, Pierrot-Deseilligny E. Inhibition of human motoneurons, probably of Renshaw origin, elicited by an

16 Rossiodromic motor discharge. J Physiol 1977;269:319-39. for Renshaw stimulation in man. Exp Neurol 1987;98:1-12.

17 Mazières L, Morin C, Pierrot-Deseilligny E. Effet de l'amplitude du réflexe test sur le niveau de facilitation ou d'inhibition des réponses monosynaptiques. J Physiol (Paris) 1984;79:65A.

18 Curtis DR, Ryall RW. The acetylcholine receptors of Renshaw cells. Exp Brain Res 1966;2:66-80.

19 Ryall RW. Cholinergic transmission in the spinal cord. In: Davidoff RA, ed. Handbook of the Spinal Cord. New York: Dekker, 1983:203-40. 